This item was submitted to Loughborough's Research Repository by the author.

Items in Figshare are protected by copyright, with all rights reserved, unless otherwise indicated.

\title{
Pressuremeter tests in municipal solid waste: measurement of shear
} stiffness

PLEASE CITE THE PUBLISHED VERSION

PUBLISHER

(C) Institution of Civil Engineers / Thomas Telford

VERSION

VoR (Version of Record)

LICENCE

CC BY-NC-ND 4.0

\section{REPOSITORY RECORD}

Dixon, Neil, R.W. Whittle, D. Russell V. Jones, and Samson Ng'ambi. 2019. "Pressuremeter Tests in Municipal Solid Waste: Measurement of Shear Stiffness". figshare. https://hdl.handle.net/2134/4618. 
This item was submitted to Loughborough's Institutional Repository (https://dspace.lboro.ac.uk/) by the author and is made available under the following Creative Commons Licence conditions.

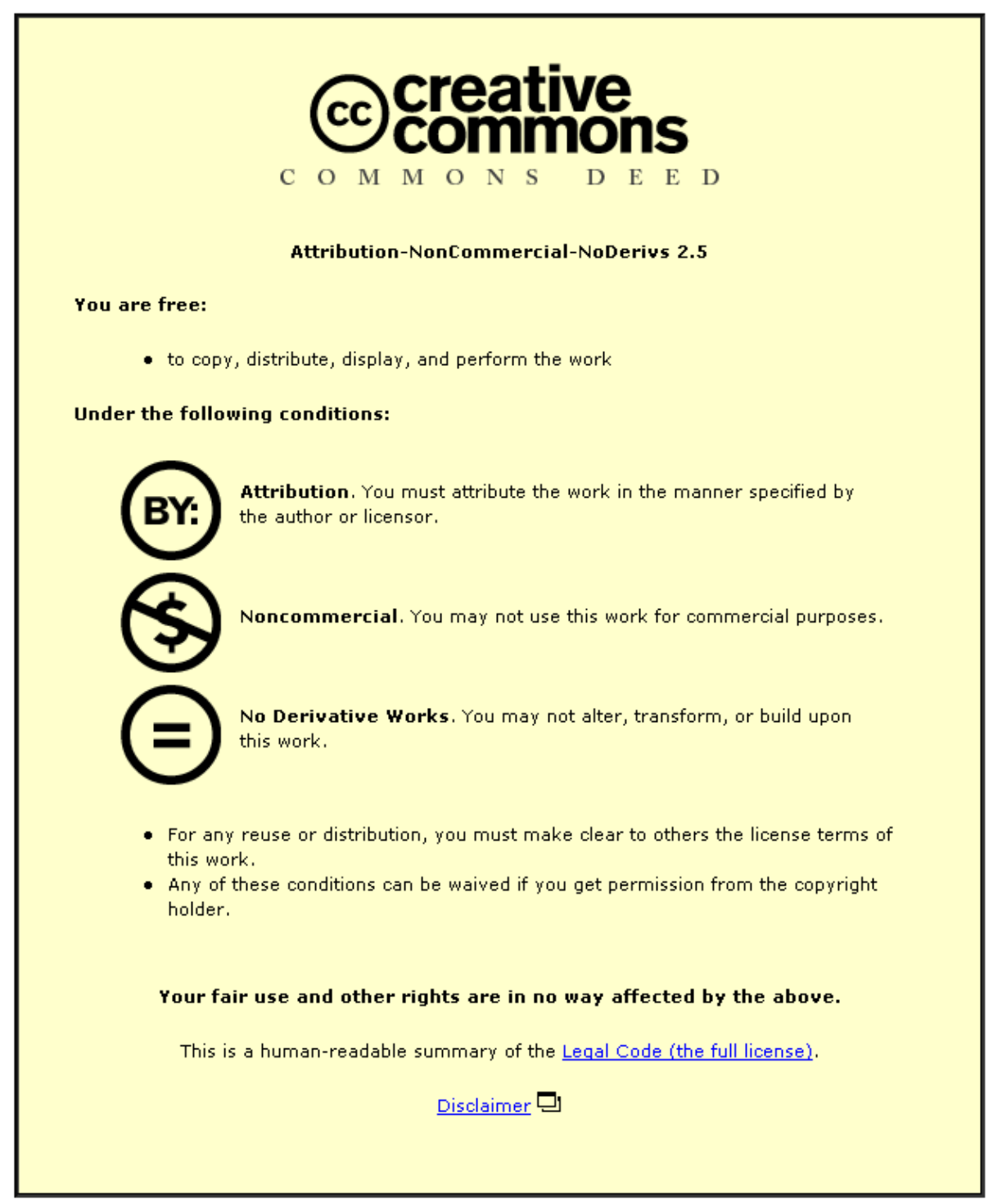

For the full text of this licence, please go to: http://creativecommons.org/licenses/by-nc-nd/2.5/ 


\title{
Pressuremeter tests in municipal solid waste: measurement of shear stiffness
}

\author{
N. DIXON*, R. W. WhitTlE $\uparrow$, D. R. V. JONES $\ddagger$ and S. NG’AMBI§
}

To assess the long-term integrity, and hence adequate performance, of landfill lining systems the designer must consider interaction between lining components and the waste body. Information on typical ranges of waste mechanical properties is required for use in numerical modelling of this interaction. This paper presents results from a programme of pressuremeter testing in municipal solid waste (MSW) carried out to measure shear stiffness properties. An optimum procedure has been developed using a high-pressure dilatometer in a preformed test pocket. Tests have been conducted in fresh and partially degraded MSW deposits. Values of shear moduli for small to intermediate strains have been obtained from series of unload-reload loops, and these show a strong relationship between shear modulus and depth. Stiffness increases with cavity strain owing to drained cavity expansion. A clear linear relationship has been found between shear stiffness and stress level. Results for fresh MSW from two landfill sites show close agreement. Good agreement has been found between shear stiffness values calculated for small strain in pressuremeter tests and shear stiffness values measured using the continuous surface wave method. They also compare well with the limited amount of information in the literature.

KEYWORDS: landfills; in situ testing; stiffness
Pour évaluer l'intégrité à long terme et donc la bonne adéquation de la performance des systèmes de doublure des décharges, le concepteur doit tenir compte de l'interaction entre les composants de doublure et le corps des déchets. Une information sur les gammes types de propriétés mécaniques des déchets est nécessaire dans la modélisation numérique de cette interaction. Cet exposé présente les résultats d'un programme d'essais au pressiomètre dans des décharges municipales à déchets solides (MSW), essais effectués pour mesurer les propriétés de rigidité au cisaillement. Un procédé optimum a été développé en utilisant un dilatomètre à haute pression dans une poche d'essai préformée. Les essais ont été menés dans des dépôts MSW frais et partiellement dégradés. Nous avons obtenus des valeurs de modules de cisaillement pour des déformations de petite à moyenne importance d'après une série de boucles déchargement-rechargement ; celles-ci montrent une forte corrélation entre les modules de cisaillement et la profondeur. La rigidité augmente en même temps que la déformation de la cavité en raison de l'expansion de cavité drainée. Nous avons trouvé une relation linéaire claire entre la rigidité au cisaillement et le niveau de contrainte. Les résultats pour des MSW frais appartenant à deux sites de décharge se correspondent étroitement. Une bonne concordance a été trouvée entre les valeurs de rigidité au cisaillement calculées pour une petite déformation dans les essais de pressiomètre et les valeurs de rigidité au cisaillement mesurées en utilisant la méthode d'onde de surface continue. Elles sont également en accord avec le peu d'informations publiées.

\section{INTRODUCTION}

Consideration of landfill lining system stability is a fundamental part of the design and regulatory process. Incorrect or incomplete assessment of stability has led to failures worldwide (Koerner \& Soong, 2000; Jones et al., 2002). In Europe, the Council of the European Union Landfill Directive (CEC, 1999) has raised the level of lining system design required by regulators (such as the Environment Agency in the UK). The occurrence of failures, the introduction of new materials and construction practices, the development of new design methods, and ongoing changes in municipal solid waste (MSW), together with the legislative need to remove the risk to human health and the environment have all contributed to the need for information on the mechanical properties of MSW. The design of landfills must consider stability both within and between elements of the lining

Manuscript received 28 November 2005; revised manuscript accepted 3 January 2006.

Discussion on this paper closes on 2 October 2006, for further details see $p$. ii.

* Department of Civil and Building Engineering, Loughborough University, UK.

$\dagger$ Cambridge Insitu, Little Eversden, Cambridge, UK.

$\$$ Golder Associates (UK) Ltd, Stanton-on-the-Wolds, UK.

$\S$ School of Science and the Environment, Coventry University, UK

(formerly Loughborough University, UK). system and within the waste to ensure that uncontrolled slippage does not occur. However, the design must also consider the long-term integrity of the lining system. Stresses, and hence strains, in both mineral and geosynthetic lining materials must be controlled. Assessment of integrity requires consideration of interaction between the waste body and lining components. This is of particular importance for the structural performance of lining systems used on steep slopes. Numerical modelling techniques are increasingly being used to aid the design of such lining systems. This establishes the need to measure relevant mechanical properties of MSW that can be used to describe its stress-strain behaviour.

It is not possible to characterise the engineering properties of waste fully, because of its heterogeneous nature, but it is important that its basic behaviour is understood and that likely ranges of the key engineering properties are known. MSW is a mixture of wastes that are primarily of residential and commercial origin. Typically, it consists of food and garden wastes, paper products, plastics, rubber, textiles, wood, ashes, and soils (both waste products and material used as cover material). A wide range of particle sizes are typically present, ranging from soil particles to large objects such as demolition waste (such as reinforced concrete and masonry). The proportion of these materials will vary from one site to another and also within a site. Lifestyle changes and legislation result in a changing waste stream over time. 
In the UK, for example, over the past few decades plastic content has increased (Watts et al., 2002), and a reduction in the amount of inert waste landfilled has occurred following introduction of the Landfill Tax. Changes in waste composition will continue to occur. For example, the CEC Landfill Directive (CEC, 1999) sets targets for reduction in biodegradable waste sent to landfill. Evaluating the engineering properties of MSW is challenging owing to the variety of materials present, the large range of particle sizes, and the structure of MSW. This last results from placement and compaction processes. Therefore, in common with testing coarse-grained soils, it is preferable to undertake in situ testing on 'undisturbed' material. To date, research has concentrated on the measurement of vertical stiffness (i.e. constrained modulus) for use in the calculation of waste settlement (e.g. Abbiss, 2001; Watts et al., 2002). This paper presents results from a programme of pressuremeter testing carried out in order to measure shear stiffness properties of MSW, to investigate issues of variability both within and between sites, and to assess the influence of degradation. The test method is outlined, measured stiffness values are presented and interpreted, and a comparison is made with the limited data on MSW shear stiffness in the literature.

\section{TEST METHOD}

An approach has been developed using standard pressuremeter equipment. This can be used to generate large strains, and measured behaviour is influenced by a relatively large volume of material surrounding the test device. These are important factors owing to the reinforced behaviour and heterogeneous nature of MSW. In addition, pressuremeters measure the average stress acting on the membrane, and hence any large variations in the waste will be averaged (i.e. point loads from individual particles). Trials were conducted using both self-boring pressuremeter (SBP) and high-pressure dilatometer (HPD) devices. Testing was carried out at two landfill sites. Most of the testing was at Calvert landfill in Buckinghamshire. This landfill has been accepting waste since 1979, and therefore wastes with a range of ages, and hence degrees of degradation, were available for testing. The waste at this landfill arrives mainly by rail from the London and Bristol areas, and comprises primarily household waste from collection rounds (i.e. there is only a small percentage of construction waste). The second landfill used was Burntstump in Nottinghamshire. This site also accepted mainly MSW, and was used to investigate the structural performance of a steep slope landfill lining system (Dixon et al., 2004) through instrumentation of the side slope lining system. Testing at Burntstump was carried out to provide stiffness information for use in numerical analysis of the barrier performance, in addition to allowing a comparison of measured stiffness values between the two sites.

An initial series of tests was conducted using an $83 \mathrm{~mm}$ diameter self-boring pressuremeter capable of producing cavity strains of up to $10 \%$. The $1.2 \mathrm{~m}$ long device had an expandable mid-section $0.5 \mathrm{~m}$ long. Three strain arms were used to measure cavity strains. The $1.25 \mathrm{~mm}$ thick membrane was protected by a Chinese lantern. The test pocket was self-bored, either from ground level or from the base of an access borehole, using water flush. Both rock roller and full face cutter drill bits were trialled; the best results were achieved using the rock roller. Slow drilling rates were experienced, and there was significant loss of water flush and a high percentage of abortive tests owing to membrane damage during inflation. The preliminary results obtained using the SBP were reported by Dixon et al. (1999).

Based on the experience of using the self-boring pressuremeter a test method was developed using a $95 \mathrm{~mm}$ diameter high-pressure dilatometer with six strain arms. The HPD has a thicker $(6 \mathrm{~mm})$ membrane, which is more robust than the SBP membrane. Larger cavity strains (up to 50\%) can be achieved with this device. This was an important consideration, because large shear strains are required if the strength of MSW is to be mobilised (e.g. Jessberger, 1994). Access boreholes were drilled using continuous flight augers and a test pocket $1.5 \mathrm{~m}$ long, and nominally $96 \mathrm{~mm}$ in diameter, was formed from the base of the access borehole using a barrel auger. All boreholes were stable, and hence uncased, as a result of the reinforced behaviour of MSW. Two of the boreholes were videoed, and visual assessment of the borehole stability, test socket uniformity and MSW composition was made. The HPD was pushed into the test pocket. In most instances this required a small force. Most of the MSW tested was in a dry state, although at Calvert above cover soil layers, typically clay-rich, perched leachate resulted in the waste having a high moisture content, with active gas generation. All tests were considered to cause drained loading (as discussed below). A key issue in using the HPD is the need to carry out a full membrane correction. A relatively large force was required to inflate the membrane in relation to that required to expand the MSW pocket. The results obtained from the SBP and HPD are comparable (see below); however, the HPD was used for most of the tests as it was more robust and generated larger strains, and each pocket formation and test took less time to complete.

\section{ANALYSIS METHODS AND RESULTS \\ Scope of testing}

In total, 36 pressuremeter tests were carried out in MSW, of which 26 were HPD tests and 10 SBP tests. Of these, 13 were in waste less than 1 year old, 15 in waste 3 to 5 years old, and 8 in waste 12 to 15 years old. Thirty tests were conducted at Calvert landfill and six at Burntstump. A total of 110 unload-reload loops were performed. Test depths were in the range $1.7-18.0 \mathrm{~m}$ below ground level. Table 1 provides a summary of the test locations and waste descriptions. The tests in 3 to 5 year old and 12 to 15 year old MSW were carried out beneath compacted clay cover layers 1-2 $\mathrm{m}$ thick. Apart from specific instances in the text where the waste is referenced by age, the MSW 5 years old or less is referred to in this paper as fresh waste, because arisings from the test depths showed little signs of degradation. The 12 and 15 year old waste is refereed to as older waste. This material was more variable: at some locations it was dry, and showed little signs of degradation, whereas at others it had a high moisture content with advanced degradation.

\section{Analysis method}

A typical plot of cavity pressure against cavity strain obtained from an HPD test in MSW is shown in Fig. 1, with key parameters indicated. The parameters are defined in the notation and discussed in the relevant sections of the paper. In all cases it is the average displacement/strain, recorded by the six measurement arms (three for the SBP) that has been used in the presentation and analysis of the results. Currently there is no analytical method available to describe the full relationship of cavity pressure against strain from tests in reinforced drained material such as MSW. This has limited the parameters that could be obtained from the tests, and specifically meant that it was not possible to obtain relevant shear strength parameters. Analysis of the pressuremeter results has concentrated on measurements of shear stiffness from unload-reload loop data. The MSW tested has a noticeable non-linear elastic characteristic (Fig. 1). Secant moduli from small to intermediate strains have been derived 
Table 1 Waste descriptions for test locations

\begin{tabular}{|c|c|c|}
\hline Site, test type and age & Depth: mbgl & Waste description \\
\hline Calvert & $4 \cdot 8$ & Paper, textiles, plastic sheets, green waste, wood (dry with little degradation*) \\
\hline HPD & $6 \cdot 4$ & Paper, textiles, plastic sheets, green waste, wood (dry with little degradation) \\
\hline \multirow[t]{4}{*}{5 year old } & $4 \cdot 1$ & Clay, $\dagger$ paper, textiles, plastic sheets, green waste, wood (dry with little degradation) \\
\hline & $5 \cdot 8$ & Clay, paper, textiles, plastic sheets, green waste, wood, wire (dry with little degradation) \\
\hline & $8 \cdot 9$ & $\begin{array}{l}\text { Paper, textiles, plastic sheets, green waste, wood, brick, concrete fragments (wet with some } \\
\text { degradation of paper) }\end{array}$ \\
\hline & $12 \cdot 0$ & Paper, textiles, plastic sheets, green waste, wood, fines (moist with degraded paper) \\
\hline \multirow[t]{2}{*}{$\begin{array}{l}\text { Calvert } \\
\text { HPD }\end{array}$} & $2 \cdot 9$ & $\begin{array}{l}\text { Plastic containers and sheets, paper, metals, concrete fragments, green waste (dry with little } \\
\text { degradation) }\end{array}$ \\
\hline & $5 \cdot 1$ & Plastic containers and sheets, paper, wire (dry with little degradation) \\
\hline \multirow[t]{5}{*}{$<1$ year old } & $7 \cdot 1$ & $\begin{array}{l}\text { Paper, wood, textiles, plastic sheets, silt-sized particles, concrete fragments (dry with little } \\
\text { degradation) }\end{array}$ \\
\hline & 8.9 & Paper, wood, concrete fragments (moist with little degradation) \\
\hline & $10 \cdot 6$ & Green waste, paper, plastic, textiles, brick fragments (moist with some degradation of paper) \\
\hline & 13.9 & Plastic sheets, paper, textiles, wood, metals (wet with some degradation of paper) \\
\hline & $15 \cdot 9$ & Paper, plastic sheets, green waste, wood, fines (wet with well-degraded paper) \\
\hline Calvert & $3 \cdot 3$ & Plastic sheet, paper, wood, textiles (dry with little degradation) \\
\hline HPD & $5 \cdot 0$ & Paper, plastic, wood, green waste (moist with some degradation) \\
\hline \multirow[t]{5}{*}{15 year old } & $8 \cdot 5$ & Paper, plastic sheets, fines, brick fragments (moist with well-degraded paper) \\
\hline & $11 \cdot 0$ & Rubber, fragments of brick, plastic sheets and paper (wet with well-degraded paper) \\
\hline & $13 \cdot 5$ & Clay, plastic containers, paper, fines (wet with well-degraded paper) \\
\hline & $16 \cdot 0$ & Wood, paper, brick fragments, plastic sheets (moist with some degradation of paper) \\
\hline & $17 \cdot 9$ & Clay, paper, wood, plastic sheets (moist with some degradation of paper) \\
\hline Burntstump & $3 \cdot 1$ & Plastic containers and sheets, paper, wood, brick fragments, metals (dry with little degradation) \\
\hline & $6 \cdot 0$ & Plastic sheets, paper, wood (dry with little degradation) \\
\hline \multirow[t]{4}{*}{$<1$ year old } & $7 \cdot 6$ & Plastic containers and sheets, metals, wood, paper (dry with little degradation) \\
\hline & $9 \cdot 6$ & Textiles, paper, sand, plastic sheets (moist with little degradation) \\
\hline & $11 \cdot 6$ & Wood, wire, paper, plastic containers and sheets (moist with little degradation) \\
\hline & $3 \cdot 6$ & Plastic containers and sheets, paper, wood (dry with little degradation) \\
\hline Calvert SBP 12 year old & $11 \cdot 0$ & Plastics, paper, textiles, metals and brick fragments in a matrix of fine particles \\
\hline Calvert SBP & All tests & Plastics, paper, textiles, metals, green waste, wood and brick fragments \\
\hline
\end{tabular}

* Degree of degradation is indicated by dark grey and black colour, fines and odour (i.e. indicating presence of a bio-film).

$\uparrow$ Clay material is from temporary cover soil layers.

$\$$ In tests using the self-boring pressuremeter, no samples were obtained from the test depth (i.e. poor return of cuttings via water flush), so waste descriptions are indicative based on arising from above and below the test location. This also means there is no direct information on moisture condition or degree of degradation.

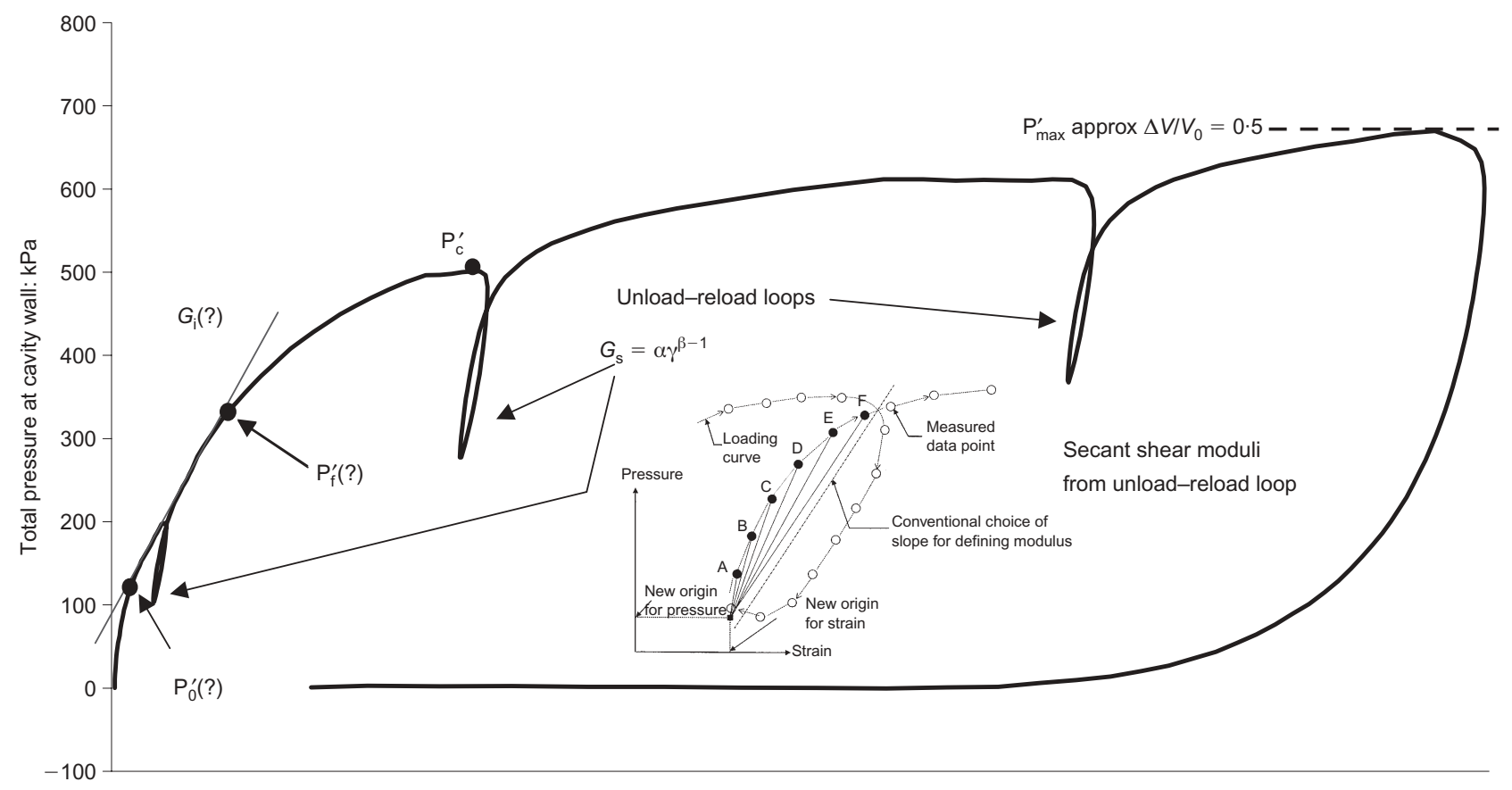

Average radial displacement of cavity wall: $\mathrm{mm}$

Fig. 1. Plot of pressure against cavity displacement showing definition of key parameters and calculation of small-strain secant shear moduli from unload-reload loops. (?) denotes potential uncertainty in calculating values 
from reloading data using the approach suggested by Bolton \& Whittle (1999). Between one and five unload-reload loops were carried out in each test, enabling measurement of shear modulus values at a range of cavity strains and hence stress states (see below). Loop strain amplitudes varied. As formation of the loop starts by unloading the material surrounding the test pocket, the waste behaves elastically throughout the unload-reload cycle as long as yield does not occur on extension. Loop stress amplitudes were controlled to ensure that the MSW did not yield, and there is no evidence from the trend of calculated stiffness values that yield occurred.

Bolton \& Whittle (1999) show that the non-linear elastic decay curve of stiffness against strain can be described by a power law, leading to the following relationship for secant shear modulus $\left(G_{\mathrm{s}}\right)$ and plane shear strain $(\gamma)$.

$$
G_{\mathrm{s}}=\alpha \gamma^{\beta-1}
$$

where $\alpha$ and $\beta$ represent the constant and exponent of non- linearity; $\beta=1$ denotes a linear elastic response, and finegrained soils produce values in the range 0.5 to $0 \cdot 6$. These two parameters are easily obtained from unload-reload cycle data plotted on log-log scales. A shear strain of $10^{-4}$ is approximately the resolution of the displacement measuring system used, and strains of $10^{-2}$ would induce yield in most soils, and therefore possibly in MSW. A summary of parameters derived from the tests is provided in Table 2.

Relationships of cavity pressure against displacement for fresh MSW, stiff clay (Gault clay) and medium dense sand are shown in Fig. 2. Pressure and displacement have been normalised using the maximum values recorded in the respective tests to aid comparison. The MSW and clay tests were conducted using HPD and the sand using an SBP. Measured MSW behaviour resembles that of sand rather than of clay. Unload-reload loops conducted at increasing cavity wall displacements show a response of increasing stiffness in both the MSW and sand tests (i.e. as indicated by the increase in average slope of the loops). This is a result of drained cavity expansion leading to increases in the

Table 2. Summary of parameters measured in HPD and SBP tests carried out in fresh and older waste

\begin{tabular}{|c|c|c|c|c|c|c|c|c|c|}
\hline Test type/Waste age & $\begin{array}{c}\text { Depth:* } \\
\text { mbgl }\end{array}$ & $\begin{array}{l}P_{0}^{\prime}: \dagger \\
\mathrm{kPa}\end{array}$ & $\begin{array}{l}P_{\mathrm{f}}^{\prime}: \dagger \\
\mathrm{kPa}\end{array}$ & $\begin{array}{l}P_{35}^{\prime}: \S \\
(\mathrm{kPa})\end{array}$ & $\begin{array}{l}G_{\mathrm{i}}: \bullet \\
\text { MPa }\end{array}$ & $\begin{array}{l}\text { Loop 1:+ } \\
\alpha(\mathrm{MPa}) / \beta\end{array}$ & $\begin{array}{l}\text { Loop 2: } \\
\alpha(\mathrm{MPa}) / \beta\end{array}$ & $\begin{array}{c}\text { Loop 3: } \\
\alpha(\mathrm{MPa}) / \beta\end{array}$ & $\begin{array}{c}\text { Loop 4: } \\
\alpha(\mathrm{MPa}) / \beta\end{array}$ \\
\hline HPD tests & $4 \cdot 8$ & 103 & 224 & - & $1 \cdot 2$ & $1 \cdot 276 / 0 \cdot 752$ & $1 \cdot 762 / 0 \cdot 760$ & & - \\
\hline Calvert: & $6 \cdot 4$ & 116 & 225 & - & $1 \cdot 3$ & $1 \cdot 716 / 0 \cdot 817$ & $4 \cdot 495 / 0 \cdot 922$ & $2 \cdot 861 / 0 \cdot 809$ & \\
\hline 5 year old MSW & $4 \cdot 1$ & 69 & 152 & 459 & 1.9 & $0.811 / 0.699$ & $1 \cdot 078 / 0 \cdot 721$ & $1 \cdot 108 / 0 \cdot 697$ & $1 \cdot 363 / 0 \cdot 687$ \\
\hline \multirow[t]{3}{*}{ under clay cover } & $5 \cdot 8$ & 74 & 200 & 701 & $2 \cdot 5$ & $2 \cdot 336 / 0 \cdot 856$ & $2 \cdot 077 / 0.776$ & $1.837 / 0.747$ & $2 \cdot 180 / 0 \cdot 723$ \\
\hline & $8 \cdot 9$ & 114 & 420 & 935 & $3 \cdot 7$ & $3 \cdot 448 / 0 \cdot 760$ & $3 \cdot 352 / 0 \cdot 750$ & $2 \cdot 352 / 0 \cdot 678$ & $2 \cdot 952 / 0 \cdot 692$ \\
\hline & $12 \cdot 0$ & 164 & 314 & 670 & $3 \cdot 8$ & $1 \cdot 289 / 0 \cdot 627$ & $2 \cdot 558 / 0 \cdot 700$ & $2 \cdot 865 / 0 \cdot 714$ & \\
\hline HPD tests & $2 \cdot 9$ & 24 & 36 & 316 & $3 \cdot 3$ & $0 \cdot 743 / 0 \cdot 755$ & $0 \cdot 624 / 0 \cdot 710$ & $0 \cdot 836 / 0 \cdot 751$ & \\
\hline Calvert: & $5 \cdot 1$ & 70 & 179 & 480 & $1 \cdot 2$ & $1 \cdot 226 / 0 \cdot 821$ & $1 \cdot 118 / 0 \cdot 745$ & $1 \cdot 073 / 0 \cdot 695$ & $1 \cdot 515 / 0 \cdot 711$ \\
\hline Fresh MSW less & $7 \cdot 1$ & 144 & 343 & 707 & $1 \cdot 7$ & $1.297 / 0 \cdot 783$ & $1 \cdot 504 / 0 \cdot 773$ & $1 \cdot 581 / 0 \cdot 728$ & $2 \cdot 484 / 0 \cdot 735$ \\
\hline \multirow[t]{4}{*}{ than 1 year old } & $8 \cdot 9$ & 130 & 268 & - & $1 \cdot 4$ & $1 \cdot 085 / 0 \cdot 949$ & $1 \cdot 262 / 0 \cdot 823$ & $1 \cdot 823 / 0 \cdot 761$ & \\
\hline & $10 \cdot 6$ & 106 & 216 & 437 & $2 \cdot 1$ & $1 \cdot 225 / 0 \cdot 717$ & $2 \cdot 215 / 0 \cdot 776$ & $1.905 / 0 \cdot 724$ & \\
\hline & $13 \cdot 9$ & 115 & 255 & 556 & 1.9 & $1 \cdot 186 / 0 \cdot 728$ & $1 \cdot 122 / 0 \cdot 698$ & $1 \cdot 317 / 0 \cdot 667$ & $1 \cdot 227 / 0 \cdot 636$ \\
\hline & $15 \cdot 9$ & 129 & 214 & 519 & $2 \cdot 1$ & $1 \cdot 063 / 0 \cdot 681$ & $1 \cdot 180 / 0 \cdot 688$ & $1 \cdot 103 / 0 \cdot 649$ & \\
\hline HPD tests & $3 \cdot 3$ & 100 & 119 & 341 & $2 \cdot 3$ & $1 \cdot 689 / 0 \cdot 783$ & $1 \cdot 125 / 0 \cdot 676$ & $1 \cdot 532 / 0 \cdot 747$ & \\
\hline Calvert: & $5 \cdot 0$ & 295 & 359 & 890 & $5 \cdot 3$ & $3 \cdot 752 / 0 \cdot 716$ & & & \\
\hline 15 year old MSW & $8 \cdot 5$ & 180 & 226 & 629 & $2 \cdot 0$ & $0 \cdot 883 / 0 \cdot 625$ & $0 \cdot 644 / 0 \cdot 556$ & $0 \cdot 775 / 0 \cdot 573$ & \\
\hline \multirow[t]{4}{*}{ under clay cover } & $11 \cdot 0$ & 280 & 569 & 939 & $2 \cdot 2$ & $3 \cdot 250 / 0 \cdot 812$ & $2 \cdot 59 / 0 \cdot 699$ & $3 \cdot 578 / 0 \cdot 734$ & \\
\hline & $13 \cdot 5$ & 172 & 213 & 325 & $0 \cdot 8$ & $0 \cdot 426 / 0 \cdot 645$ & $0 \cdot 561 / 0 \cdot 667$ & & \\
\hline & $16 \cdot 0$ & 312 & 423 & 1111 & $15 \cdot 8$ & $1 \cdot 816 / 0 \cdot 594$ & $2 \cdot 141 / 0 \cdot 640$ & $2 \cdot 251 / 0 \cdot 643$ & \\
\hline & $17 \cdot 9$ & 366 & 466 & 1029 & $6 \cdot 5$ & $2 \cdot 696 / 0 \cdot 653$ & $3.739 / 0.704$ & & \\
\hline HPD tests & $3 \cdot 1$ & 5 & - & 93 & $0 \cdot 8$ & $0 \cdot 972 / 0 \cdot 880$ & $2 \cdot 138 / 0 \cdot 920$ & & \\
\hline Burntstump: & $6 \cdot 0$ & 91 & 152 & 616 & $4 \cdot 6$ & $0 \cdot 826 / 0 \cdot 690$ & $1.527 / 0.750$ & $1 \cdot 386 / 0 \cdot 700$ & \\
\hline Fresh MSW less & $7 \cdot 6$ & 70 & 232 & 625 & $4 \cdot 4$ & $2 \cdot 482 / 0 \cdot 860$ & $3 \cdot 208 / 0 \cdot 820$ & $3 \cdot 377 / 0 \cdot 800$ & $3 \cdot 133 / 0 \cdot 780$ \\
\hline \multirow[t]{3}{*}{ than 1 year old } & $9 \cdot 6$ & 100 & - & - & $1 \cdot 1$ & $0 \cdot 810 / 0 \cdot 820$ & $0.992 / 0.830$ & $1 \cdot 082 / 0 \cdot 800$ & \\
\hline & $11 \cdot 6$ & 100 & - & 515 & $3 \cdot 5$ & $2 \cdot 167 / 0 \cdot 810$ & $2 \cdot 090 / 0 \cdot 760$ & $2 \cdot 021 / 0 \cdot 710$ & $2 \cdot 175 / 0 \cdot 710$ \\
\hline & $3 \cdot 6$ & 107 & 197 & - & $19 \cdot 0$ & $3 \cdot 791 / 0 \cdot 770$ & $3.669 / 0 \cdot 730$ & $8 \cdot 631 / 0 \cdot 830$ & \\
\hline SBP test & $11 \cdot 0$ & 136 & 324 & - & $4 \cdot 1$ & $3 \cdot 413 / 0 \cdot 71$ & $2 \cdot 318 / 0 \cdot 65$ & $2 \cdot 341 / 0 \cdot 66$ & $1 \cdot 547 / 0 \cdot 59$ \\
\hline Calvert: 12 year old & & & & & & & & & \\
\hline MSW under clay cover & & & & & & & & & \\
\hline SBP tests & $3 \cdot 5$ & 46 & 97 & - & $1 \cdot 1$ & $0 \cdot 677 / 0 \cdot 700$ & & & \\
\hline Calvert: & $4 \cdot 5$ & 42 & 71 & - & 0.7 & $0.530 / 0.78$ & $0.579 / 0.76$ & $0 \cdot 664 / 0 \cdot 76$ & $0.506 / 0.69$ \\
\hline 1 to 3 year old & $5 \cdot 5$ & 63 & 133 & - & $2 \cdot 1$ & $0 \cdot 957 / 0 \cdot 69$ & $2 \cdot 363 / 0 \cdot 81$ & $0 \cdot 894 / 0 \cdot 67$ & $1 \cdot 020 / 0 \cdot 68$ \\
\hline \multirow[t]{6}{*}{ MSW under clay cover } & $6 \cdot 5$ & 76 & 96 & - & $5 \cdot 6$ & $3 \cdot 207 / 0.77$ & $1 \cdot 831 / 0.69$ & $1 \cdot 187 / 0 \cdot 64$ & \\
\hline & $10 \cdot 7$ & 55 & - & - & $0 \cdot 8$ & $1 \cdot 284 / 0 \cdot 89$ & $0 \cdot 926 / 0 \cdot 78$ & $1 \cdot 378 / 0 \cdot 81$ & $1 \cdot 882 / 0 \cdot 84$ \\
\hline & $3 \cdot 8$ & 20 & 24 & - & 0.9 & $0 \cdot 570 / 0 \cdot 81$ & $1 \cdot 108 / 0 \cdot 85$ & & \\
\hline & $1 \cdot 7$ & 77 & - & - & $7 \cdot 8$ & $0 \cdot 490 / 0 \cdot 59$ & $0.982 / 0.68$ & & \\
\hline & $2 \cdot 5$ & 44 & 65 & - & $0 \cdot 8$ & $0 \cdot 287 / 0 \cdot 60$ & $0 \cdot 454 / 0 \cdot 68$ & & \\
\hline & $3 \cdot 5$ & 56 & 63 & - & $1 \cdot 3$ & $0 \cdot 482 / 0 \cdot 71$ & $0 \cdot 684 / 0 \cdot 77$ & & \\
\hline
\end{tabular}

* Depth is metres below ground level to the centre of the pressuremeter measuring section.

$\dagger P_{0}^{\prime}$ is the estimate of cavity reference pressure derived from either Marsland \& Randolph (1977) technique or curve-fitting (Whittle, 1999).

$\ddagger P_{\mathrm{f}}^{\prime}$ is the estimate of cavity pressure when yield first occurs in material adjacent to pressuremeter.

$\S P_{35}^{\prime}$ is the pressure reached at the reference cavity strain of $35 \%$.

I $G_{\mathrm{i}}$ is the initial shear modulus taken from the slope of the loading curve prior to first yield; linear elasticity is assumed.

${ }^{+}$Loop 1 (and subsequent loops): every unload-reload cycle has been described by a power law (Bolton \& Whittle, 1999) where $\alpha$ and $\beta$ are the constant (in MPa) and exponent of linearity respectively. Secant shear modulus $G_{\mathrm{s}}$ is given by $G_{\mathrm{s}}=\alpha \gamma^{\beta}-1$ where $\gamma$ is any plane shear strain in the range $10^{-4}$ to $10^{-2}$. 


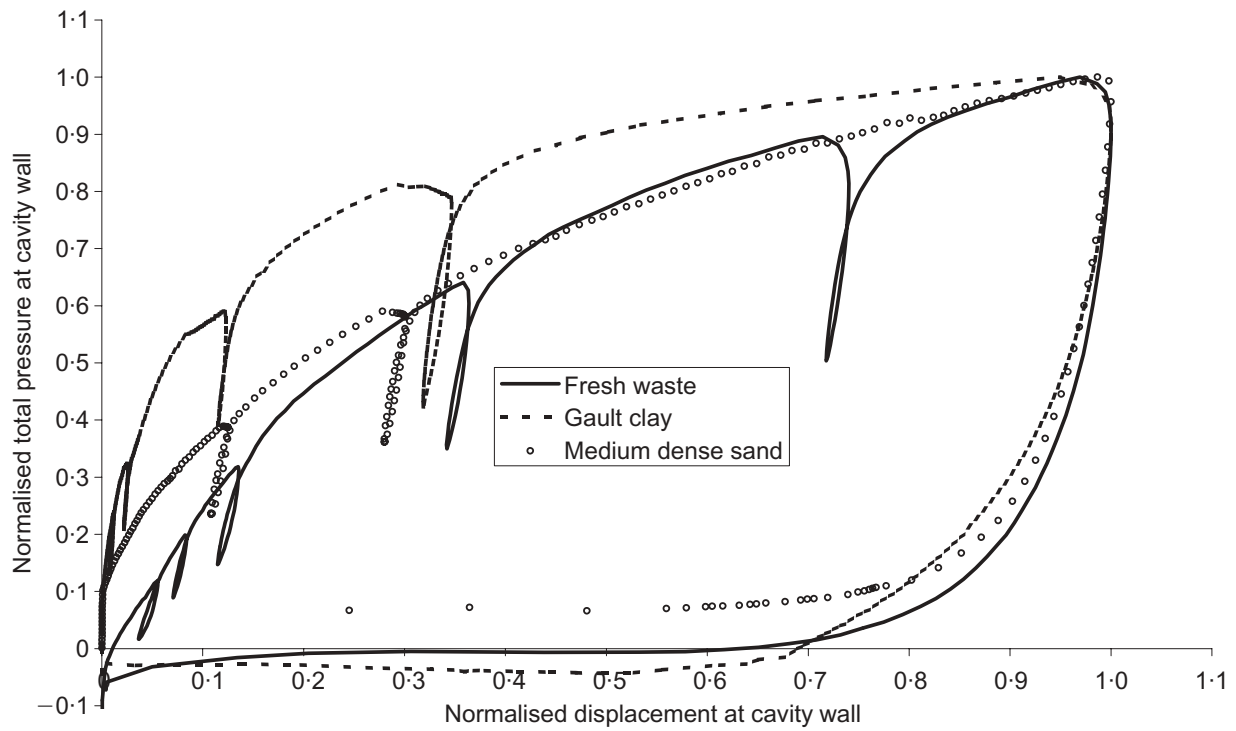

Fig. 2. Typical plots of pressure against cavity displacement for fresh MSW, Gault clay and a medium dense sand. Data have been normalised by maximum pressure and displacement achieved in each test

mean effective stress, and hence the stiffness, of the MSW/ sand surrounding the pressuremeter. Undrained expansion with no change in stiffness occurs in the clay test. The drained behaviour of the MSW is consistent with observations of samples taken from test locations, which had low moisture contents. These are associated with the waste being partially saturated, and therefore drainage occurs because of the change in volume of the air. A key difference between the behaviour of MSW and that of sand is the less stiff response of MSW in the initial phase of cavity expansion. This can result from lower material stiffness and/or a larger zone of disturbance in the HPD MSW tests (see below).

\section{Parameters obtained from the loading curve}

Values of cavity reference pressure $\left(P_{0}^{\prime}\right)$ were estimated using the Marsland \& Randolph (1977) and curve-fitting (Whittle, 1999) methods. The Marsland \& Randolph method is not valid for tests in drained materials with non-linear elastic properties, such as MSW. However, their analysis principle has been used to set an upper limit to the estimates of $P_{0}^{\prime}$. For each test an assessment of the best estimate of $P_{0}^{\prime}$ was made based on a consideration of the degree of disturbance resulting from probe insertion. This was indicated by the shape and consistency of the initial part of the cavity pressure-displacement curve. Estimated values of $P_{0}^{\prime}$ are

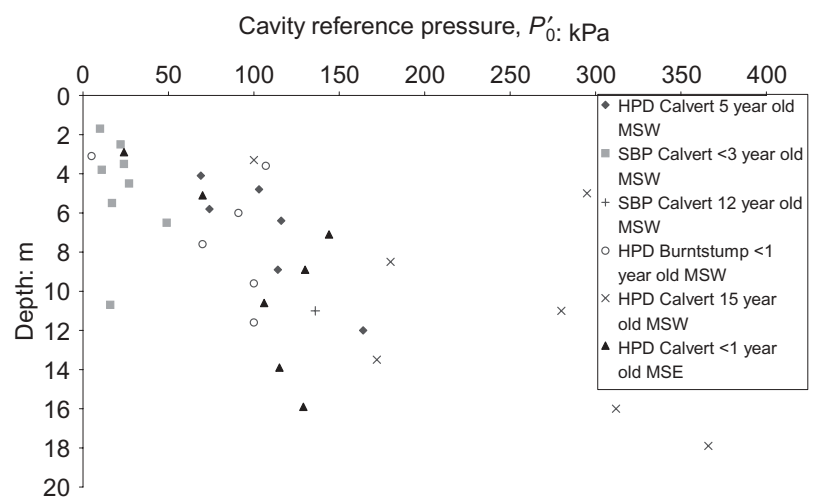

Fig. 3. Cavity reference pressure against depth below ground level (all tests) given in Table 2 and plotted against depth below ground level in Fig. 3. There is a general trend of increasing pressure with depth for both the fresh and the older waste, but there is considerable scatter. Values of pressure at first yield $\left(P_{\mathrm{f}}^{\prime}\right)$ are given in Table 2. They have been estimated from the curve of cavity pressure against displacement as being the transition point between linear and non-linear behaviour. There is no clear relationship of increasing $P_{\mathrm{f}}^{\prime}$ with depth, and all sets of data show significant scatter. Initial shear modulus $\left(G_{\mathrm{i}}\right)$ is taken from the slope of the loading curve prior to first yield, with liner elasticity assumed. Values are given in Table 2 and plotted against depth below ground level in Fig. 4. There is a general trend of increasing $G_{\mathrm{i}}$ with depth, although again there is significant scatter.

The maximum pressure reached in each test, denoted $P_{\max }^{\prime}$, can be used as a comparison parameter. It is related to limit pressure but will be less than true limit pressure. This is reached at $\Delta V / V=1$, where $V$ is the current volume of the cavity. None of the tests in MSW expands the cavity sufficiently far to measure this directly, and the analysis is too uncertain to permit extrapolation. Tests made with an HPD taken to maximum expansion give $P_{\max }^{\prime}$ values for a cavity strain of $50 \%$, equivalent to $\Delta V / V=0 \cdot 5$. Note that this is the definition of limit pressure used for interpretation of Ménard pressuremeters. However, in most HPD tests, $50 \%$ average cavity strain was not achieved, because non-

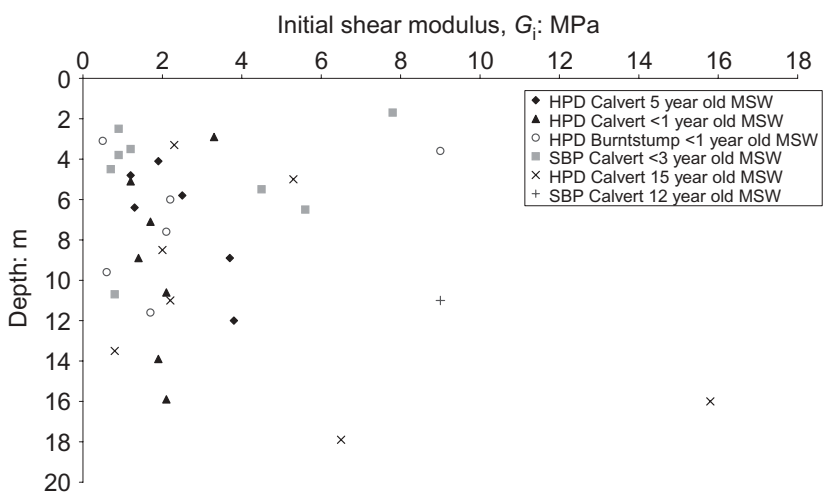

Fig. 4. Initial shear modulus against depth below ground level (all tests) 
uniform cavity expansion resulted in individual strain arms reaching maximum travel. Therefore, to enable comparison between tests, cavity pressures at a reference cavity strain of $35 \%\left(P_{35}^{\prime}\right)$ are plotted against depth in Fig. 5. This reference cavity strain is calculated using the cavity expansion to obtain $P_{0}^{\prime}$ as the strain origin in each test. This allows the disturbance caused by probe insertion to be considered. Tests that did not achieve the reference cavity strain of $35 \%$ are excluded from Fig. 5 (i.e. including all of the SBP tests).

\section{Shear stiffness}

Secant shear moduli $\left(G_{\mathrm{s}}\right)$ values have been calculated for shear strains in the range 0.0001 to 0.01 using the reload portion of unload-reload loops and applying the approach proposed by Bolton \& Whittle (1999) and given in equation (1). Fig. 6 shows secant shear modulus against shear strain for successive unload-reload loops from selected tests conducted in fresh waste at Calvert and Burntstump. Shear strains are related to the start of the reload curve (i.e. they have a local origin, as shown in Fig. 1).

Shear modulus derived from a pressuremeter unloadreload loop is dependent on the average stress level in the material when the cycle is initiated. In an undrained cavity expansion this means that successive cycles give similar values of stiffness for the same strain change. In a drained expansion, successive cycles give an increasingly stiff response, as shown in Fig. 6, because the mean effective stress around the cavity is increasing. A simple approach has been adopted to correct for this. Robertson (1982) proposed that

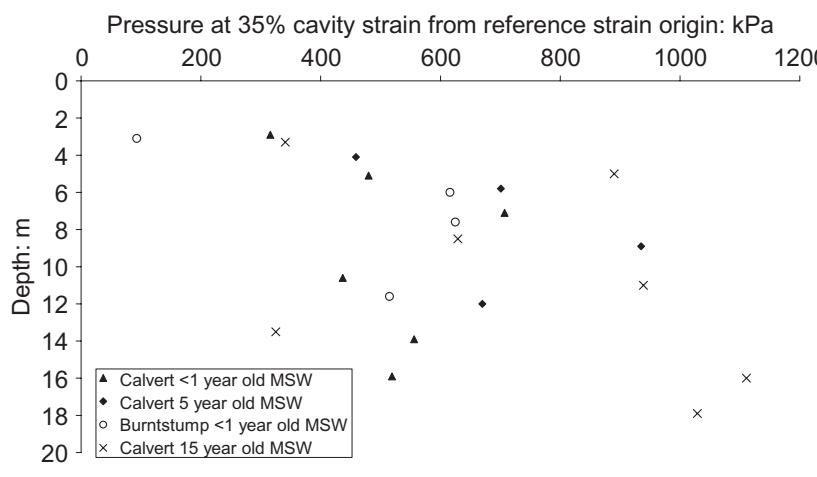

Fig. 5. Pressure achieved in each test at reference cavity strain of $35 \%$, plotted against depth the mean octahedral effective stress $\left(\sigma_{\mathrm{AV}}^{\prime}\right)$ can be approximated by $P_{\mathrm{c}}^{\prime} / 2$, where $P_{\mathrm{c}}^{\prime}$ is the measured radial stress at the cavity wall at the commencement of unloading for a loop. Bellotti et al. (1989) suggest that unload-reload values be adjusted to the in situ mean effective stress $\left(\sigma_{0}^{\prime}\right)$, applying the formula proposed by Janbu (1963). Using the nomenclature of equation (1), this leads to

$$
\alpha_{\mathrm{c}}=\alpha\left(\frac{2 \sigma_{0}^{\prime}}{P_{\mathrm{c}}^{\prime}}\right)^{n}
$$

where $\alpha_{\mathrm{c}}$ is the constant modified for stress level. Bellotti et al. (1989) quote values for modulus exponent $n$ of 0.4 to $0 \cdot 5$. A value of $0 \cdot 6$ has been reported for dense Thanet sand, but there is no information on possible values for MSW. However, following the simplified approach suggested by Robertson (1982), it is assumed for the tests in MSW that $n$ can be approximated by $0 \cdot 5$. In addition, because the estimates of in situ horizontal stress are not reliable owing to disturbance caused by test pocket formation and pressuremeter insertion, the stress level adopted for adjustment of the MSW data is the in situ effective vertical stress calculated from the overburden pressure (i.e. based on the depth of the test location below ground level and assuming an MSW unit weight of $10 \mathrm{kN} / \mathrm{m}^{2}$, which is typical for fresh MSW placed using good compaction practices; Dixon \& Jones, 2005).

Figure 7 shows secant shear modulus values corrected for mean effective stress using equation (2) $\left(G_{\mathrm{s} \text { cor }}\right)$ against shear strain, for the same tests on fresh MSW presented in Fig. 6. Secant shear stiffness values normalised using mean octahedral effective stress $\left(G_{\mathrm{s}} / \sigma_{\mathrm{AV}}^{\prime}\right)$ are plotted against shear strain in Fig. 8 for Calvert and Burntstump tests on fresh MSW (where $\sigma_{\mathrm{AV}}^{\prime}$ is approximated as $P_{\mathrm{c}}^{\prime} / 2$ ). Fig. 9 shows a similar plot for both fresh and older MSW. Secant shear modulus values $\left(G_{\mathrm{s}}\right)$ have been calculated at 0.001 strain (i.e. $0 \cdot 1 \%$ ) from each reload loop, and these are plotted against mean octahedral effective stress at commencement of unloading for the loop $\left(\sigma_{\mathrm{AV}}^{\prime}\right)$ in Fig. 10.

\section{DISCUSSION}

Validity of test method

Relationships of cavity pressure against strain obtained using HPD and SBP are comparable and consistent, as demonstrated by the agreement of parameters obtained from the loading curves using the two devices (e.g. Figs 3, 4, 8

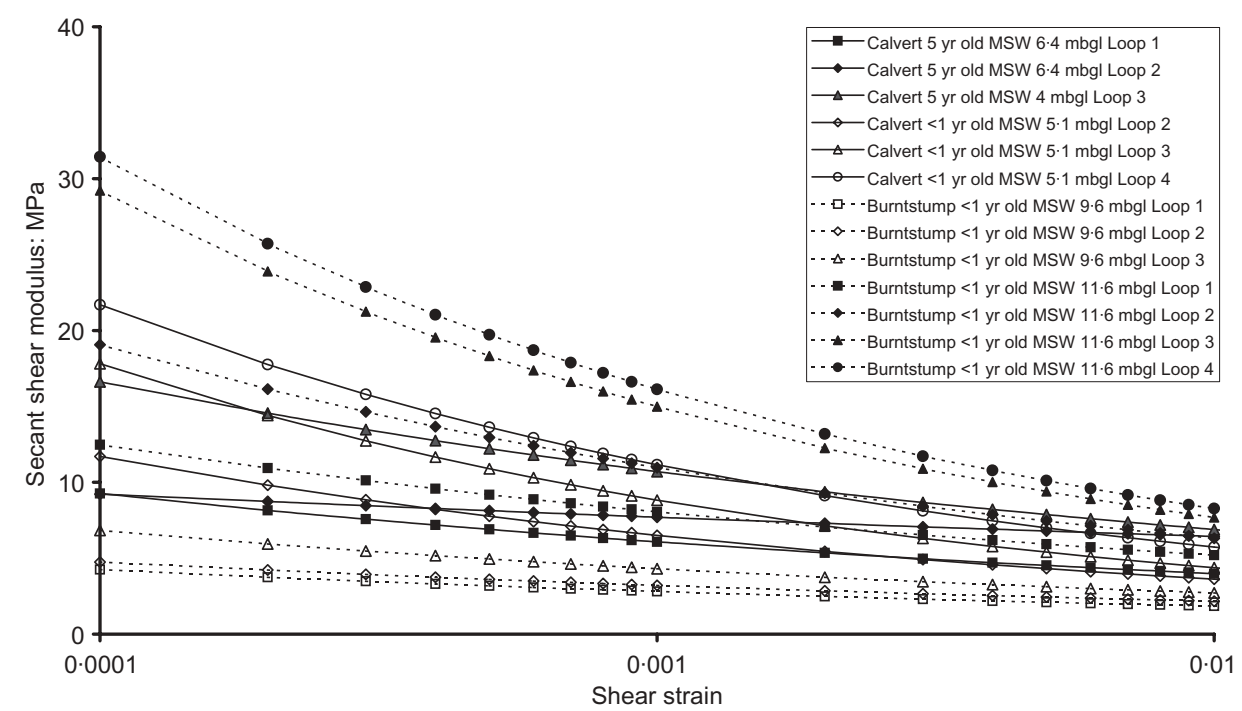

Fig. 6. Secant shear modulus from unload-reload loops plotted against shear strain for fresh waste (selected tests) 


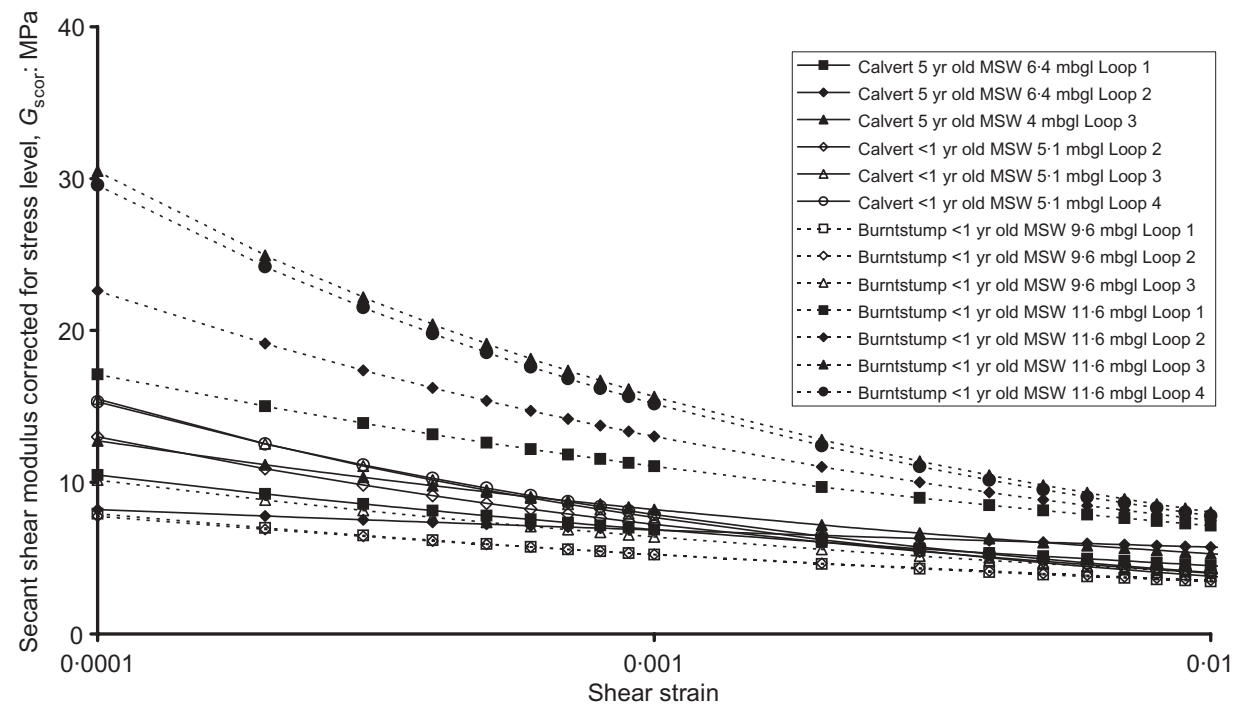

Fig. 7. Secant shear modulus corrected for stress level plotted against shear strain for fresh waste (tests shown in Fig. 6)

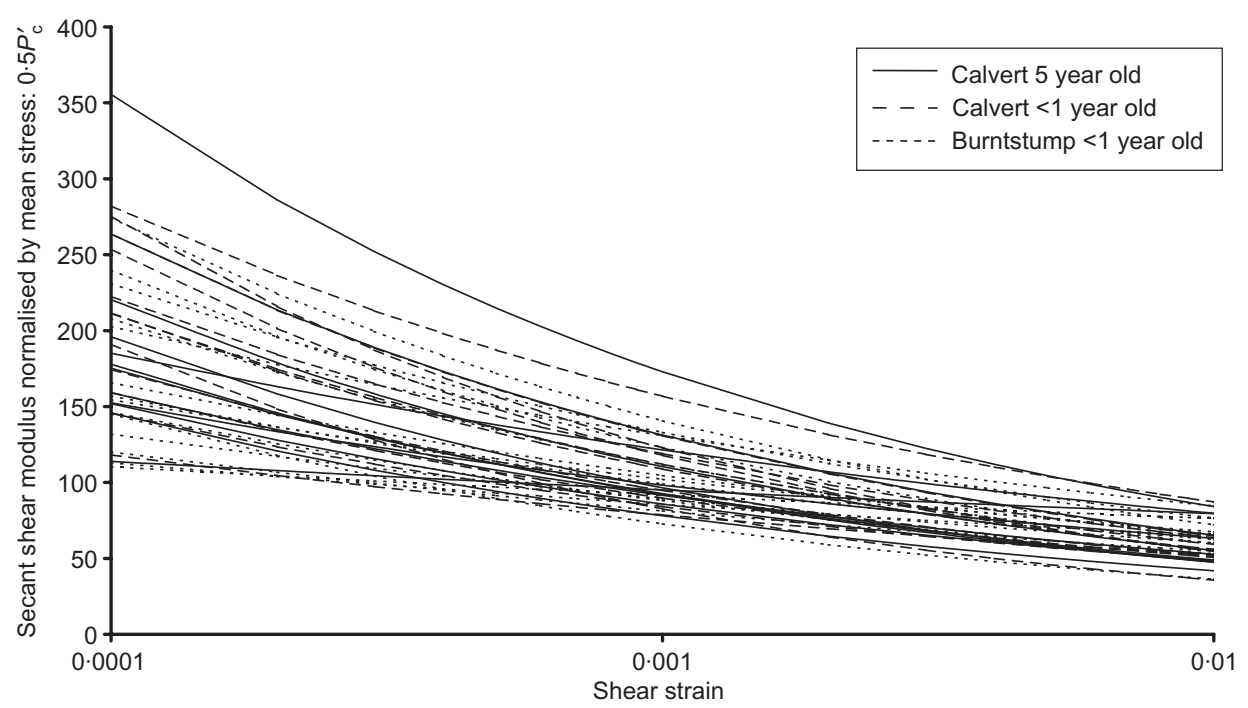

Fig. 8. Secant shear modulus normalised by mean stress at start of loop plotted against shear strain for fresh waste (all tests)

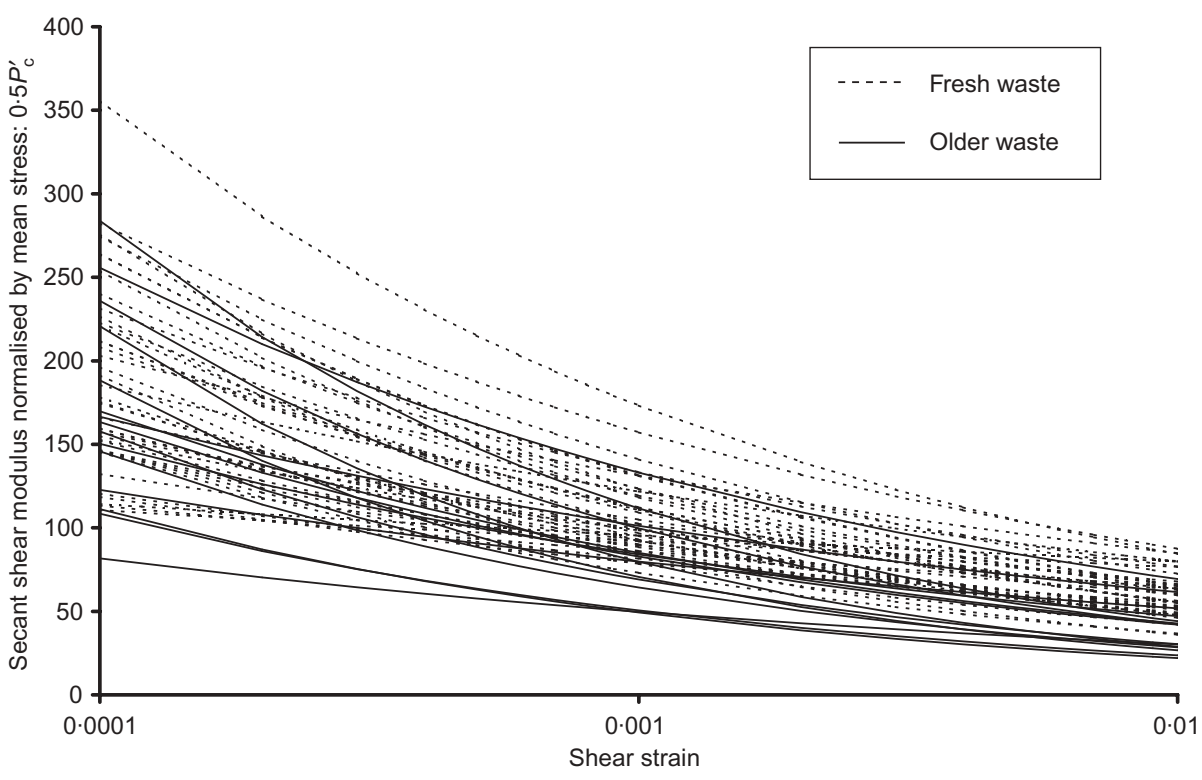

Fig. 9. Secant shear modulus normalised by mean stress at start of loop plotted against shear strain for fresh and older waste 


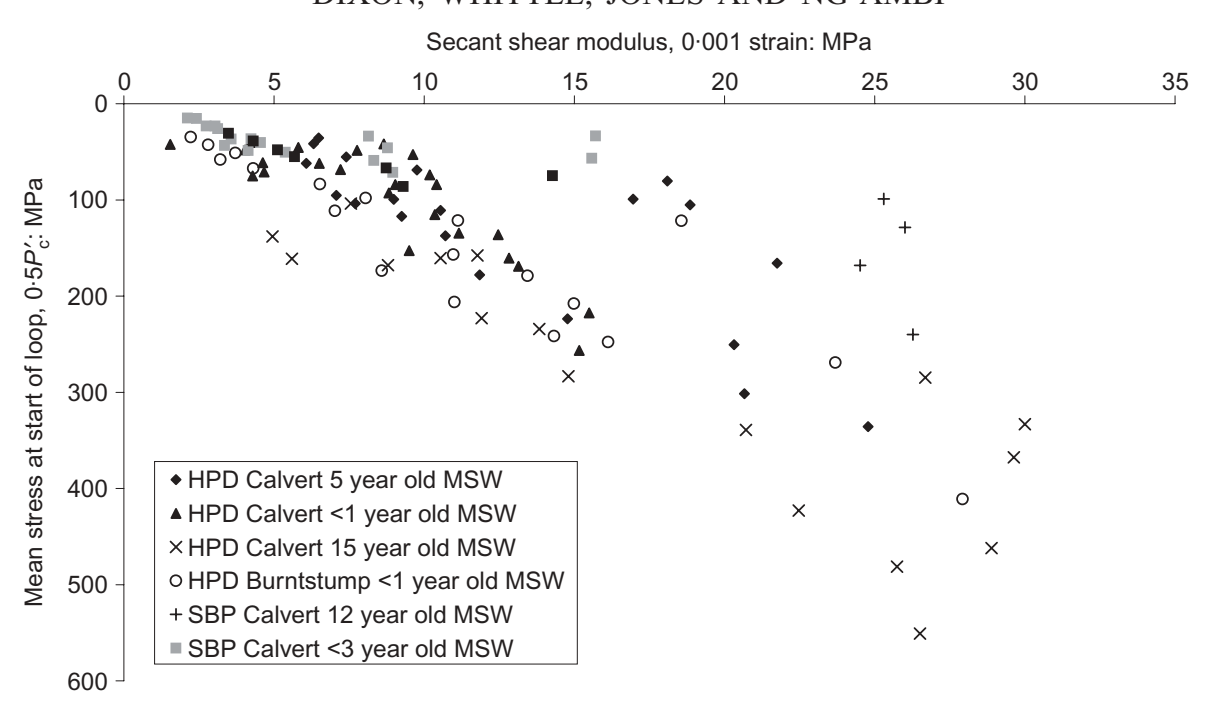

Fig. 10. Secant shear modulus from unload-reload loops for $0 \cdot 001$ shear strain plotted against mean stress at start of loop (all tests)

and 10). Usually, the SBP is employed in coarse-grained soils in an attempt to minimise disturbance and obtain information on in situ horizontal stress. For tests in MSW, slow self-boring rates, the limited cavity strains achievable and susceptibility of the membrane to damage have led to a recommendation to use the more robust HPD installed in a pre-formed socket. There are many similarities between the drained behaviour under stress of MSW and that of soil, which allow analysis methods developed for soil to be applied to the description of waste behaviour. However, a current limitation of the test method is that it is not at present possible to provide information on shear strength owing to the large strains required to cause shear failure in these reinforced materials.

\section{Disturbance}

Both SBP and HPD test methods result in disturbance of MSW surrounding the test pocket. This is due to the highly heterogeneous nature of waste, its low density and the presence of large particles, all of which make it difficult to cut a uniform-diameter socket without disturbing the surrounding material. Unlike tests in soil, individual particles may have to be cut (e.g. cores were made through sheaths of paper, bricks, pieces of wood and plastic). Cored particles will tend to displace downwards under pressure of the cutting shoe owing to poor support from the relatively low density and low stiffness of the surrounding waste body. Despite this disturbance, visual inspection by video of selected test sockets showed that they had a relatively uniform diameter. This was also demonstrated in most HPD tests by the similar performance of pairs of diametrically opposite displacement measurement arms during inflation of the membrane (i.e. a hollow on one side of the borehole would result in one or more arms recording large displacements at low pressure). Test pockets were formed using a barrel auger with a diameter $1 \mathrm{~mm}$ larger than the pressuremeter. Following removal of the barrel auger the waste expanded into the socket prior to insertion of the pressuremeter. This was indicated by the need to apply a small force in order to insert the pressuremeter into what was originally an oversized hole. For each loop, secant shear modulus $\left(G_{\mathrm{s}}\right)$ has been calculated for a strain of 0.001 (i.e. based on the local strain axis), normalised with respect to octahedral mean stress $\left(\sigma_{\mathrm{AV}}^{\prime}\right)$, and plotted against cavity strain at the start of loop expansion calculated using the original cavity radius (Fig. 11). Larger values of normalised stiffness are associated with cavity strains less than $5 \%$, and this could indicate the typical extent of the disturbed waste zone around the test socket. In some tests, the shallow angle (i.e. low stiffness) indicated by the initial part of the plot of pressure against strain demonstrated a high degree of disturbance caused during test pocket formation. The influence of disturbance on the measured parameters is discussed below.

\section{MSW variability}

It is to be expected that MSW will have mechanical properties that vary spatially. It is a heterogeneous and highly structured material, influenced by site waste acceptance criteria, placement conditions and site management factors (e.g. thickness and spacing of temporary cover layers used to control water ingress, odour and litter). Composition of MSW at a given site might be relatively uniform if a large sample is considered. However, at individual test locations, the specific waste composition, structure and stress state of the MSW surrounding the test pocket will vary. Table 1 provides waste descriptions for the test locations; however, unlike soils, this information is only indicative of the material surrounding the test pocket and hence controlling the measured behaviour. Samples retrieved using the barrel auger were highly disturbed, with individual particles

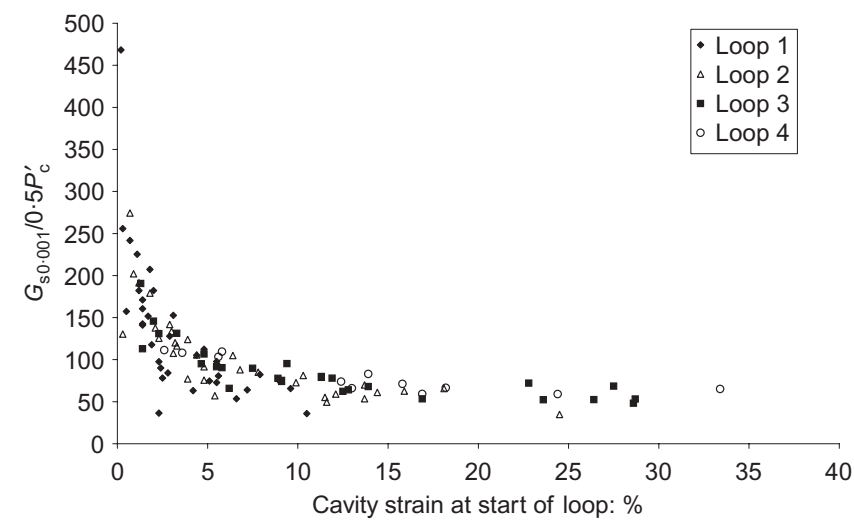

Fig. 11. Secant shear modulus from unload-reload loops for 0.001 shear strain normalised by mean stress at start of loop plotted against cavity strain at start of loop (all tests) 
degraded by the drilling process. Measured mechanical properties will show significant variability in response to waste variability. In older waste there is the added influence of degradation. At test locations in the older material the degree of waste degradation varied with depth. At Calvert, waste immediately above the clay cover soil layers was typically wetter and more degraded than that below the cover layers. Despite this variability, testing to obtain information on mechanical behaviour is still valid, as the aim is to provide guidance on possible ranges of the key parameters, rather than to propose site- and location-specific values.

\section{Parameters obtained from the loading curve}

Figures 3, 4, and 5 show the distribution with depth of $P_{0}^{\prime}, G_{\mathrm{i}}$ and $P_{35}^{\prime}$ respectively. As expected for a drained particulate material, all show a general trend of increase with depth, and hence mean stress. However, there is significant scatter in all plots. For $P_{0}^{\prime}$ and $G_{\mathrm{i}}$ this is likely to be due primarily to disturbance caused by formation of the test pocket and probe insertion. The initial part of the loading curve (i.e. cavity strains up to $5 \%$ ) is typically used to obtain these parameters, and this section is likely to be modified by disturbance, as discussed above. Scatter of the data will also be a reflection of the varying composition of the MSW surrounding test pockets, as indicated in Table 1, and to a lesser extent of the subjective nature of the methods used to obtain the parameters. The tests in older waste produced greater scatter of $P_{0}^{\prime}$ (Fig. 3). There is insufficient information to confirm the cause, but it is likely to be a result of increased variation of the MSW owing to different degrees of degradation and/or greater disturbance caused by pressuremeter insertion into the older waste. The waste was found to be more degraded above cover soil layers, as described above. The older waste does, however, have higher $P_{0}^{\prime}$ values than the fresh waste. Values of cavity reference pressure obtained using the SBP are lower than those obtained with the HPD. The reason for this is not known.

The main body of data indicates only a small increase in $G_{\mathrm{i}}$ with depth (i.e. in the order of $1 \mathrm{MPa}$ from 2 to $15 \mathrm{~m}$ below ground level). Initial shear modulus values for fresh waste at Calvert and Burntstump are comparable, but there is significant scatter caused by high modulus value outliers (Fig. 4). Most of the calculated $G_{\mathrm{i}}$ values could have been modified by disturbance, as discussed below. The presence of varying amounts of stiffer, soil-like materials at the test location will also have an influence. Construction rubble (e.g. bricks) was found in the arisings from some of the test locations where high $G_{1}$ values were measured. Given the low level of confidence in the values of ar $P_{0}^{\prime}$ and $G_{\mathrm{i}}$, there is little merit in considering ratios of $G_{\mathrm{i}} / P_{0}^{\prime}$. Although there is also relatively low confidence in the measured values of pressure at first yield $\left(P_{\mathrm{f}}^{\prime}\right)$, owing to disturbance, the results for both the fresh and the older waste are in the range $0 \cdot 15$ $0.6 \mathrm{MPa}$, which is in general agreement with those obtained by Gotteland et al. (1995) for 1 to 4 year old MSW. Values in the range $0 \cdot 27-1 \cdot 2 \mathrm{MPa}$ were reported for a limited series of Ménard tests.

The pressure values at the reference cavity strain of $35 \%$, regardless of the age of the waste, follow a trend of increasing with depth (Fig. 5), although again there is considerable variability. Only tests in the 15 year old waste produced maximum cavity pressures (i.e. denoted by flattening of the curve of pressure against strain at large cavity strains). Gotteland et al. (1995) obtained values in the range 0.35$1.4 \mathrm{MPa}$ from Ménard tests on 1 to 4 year old MSW, which is comparable to values from HPD tests. As discussed above, the Ménard test limit pressure is equivalent to a cavity strain of $50 \%$ in the HPD.

\section{Shear stiffness}

Figure 6 demonstrates increases in secant shear modulus with subsequent unload-reload loops performed at the same test location. This is a result of increasing mean stress, and hence stiffness, in the MSW adjacent to the cavity during drained expansion. Correction for the increasing mean stress results in a closer agreement between shear modulus values calculated using different loops, as shown in Fig. 7. Normalised relationships between shear stiffness and shear strain for fresh MSW tested at Calvert and Burntstump show close agreement and fall within a relatively narrow band (Fig. 8). These results confirm that MSW behaviour is related to mean stress conditions and is consistent for MSW of the same age from different sources. Secant shear stiffness normalised by mean octahedral effective stress $\left(G_{\mathrm{s}} / \sigma_{\mathrm{AV}}^{\prime}\right)$ provides a useful dimensionless parameter for modelling applications. Fig. 9 shows that, although there is some overlap with the fresh waste data, the range of normalised shear modulus values for older waste is located in the bottom two thirds of the fresh waste range and extends below the fresh waste values. This shows that the older waste is less stiff for a given value of mean effective stress. The plot of secant shear modulus (calculated at 0.001 strain) against mean octahedral effective stress at commencement of unloading for the loop (Fig. 10) also shows that the older waste is less stiff for a given level of mean stress. The figure shows the close agreement between the values for fresh MSW at Calvert and Burntstump.

Following correction of secant shear stiffness moduli for strain (i.e. by selection of a common strain amplitude over which the secant value is calculated) and mean stress (i.e. using the relationship given in equation (2) to take account of the change in stiffness resulting from drained cavity expansion), it is possible to plot the variation of corrected secant shear stiffness $\left(G_{\mathrm{s}}\right.$ cor $)$ with depth below ground level (Fig. 12). Data from all unload-reload loops are shown. A

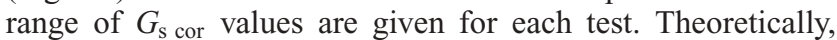
if the correction applied for mean stress is valid, all the loops in a given test should give the same value of shear modulus. It can be seen that, for a majority of the tests, variation in shear modulus from the loops is relatively small. This indicates that the correction applied is appropriate, although not perfect. Disturbance will modify the measured shear stiffness for loops carried out at small cavity strains, and these values are unlikely to show consistent trends with values obtained from latter loops. This could explain some of the observed differences between loops of corrected shear stiffnesses. Both the magnitude and the distribution of values for the fresh MSW at Calvert and Burntstump are comparable. The 5 year old waste at Calvert appears to be slightly stiffer at depths over $5 \mathrm{~m}$, but this is based on a small amount of data. The older MSW is again shown to have low shear stiffness in comparison with the fresh waste when values are corrected for mean stress.

Small-strain shear moduli values have been measured at the pressuremeter test locations (Calvert only) using the continuous surface wave method (Moxhay et al., 2001). Distributions of shear modulus $\left(G_{0}\right)$ calculated from shear wave velocities have been compared with small-strain pressuremeter secant shear stiffness values $\left(G_{\mathrm{s}}\right)$ calculated for a shear strain of 0.0001 . These were obtained from the first unload-reload loop in each test (Fig. 13). Values of waste $G_{0}$ in the literature are also included for comparison. Fig. 13 shows the $G_{0}$-depth relationships measured at the locations of the Calvert pressuremeter tests on 1,5 and 15 year old 


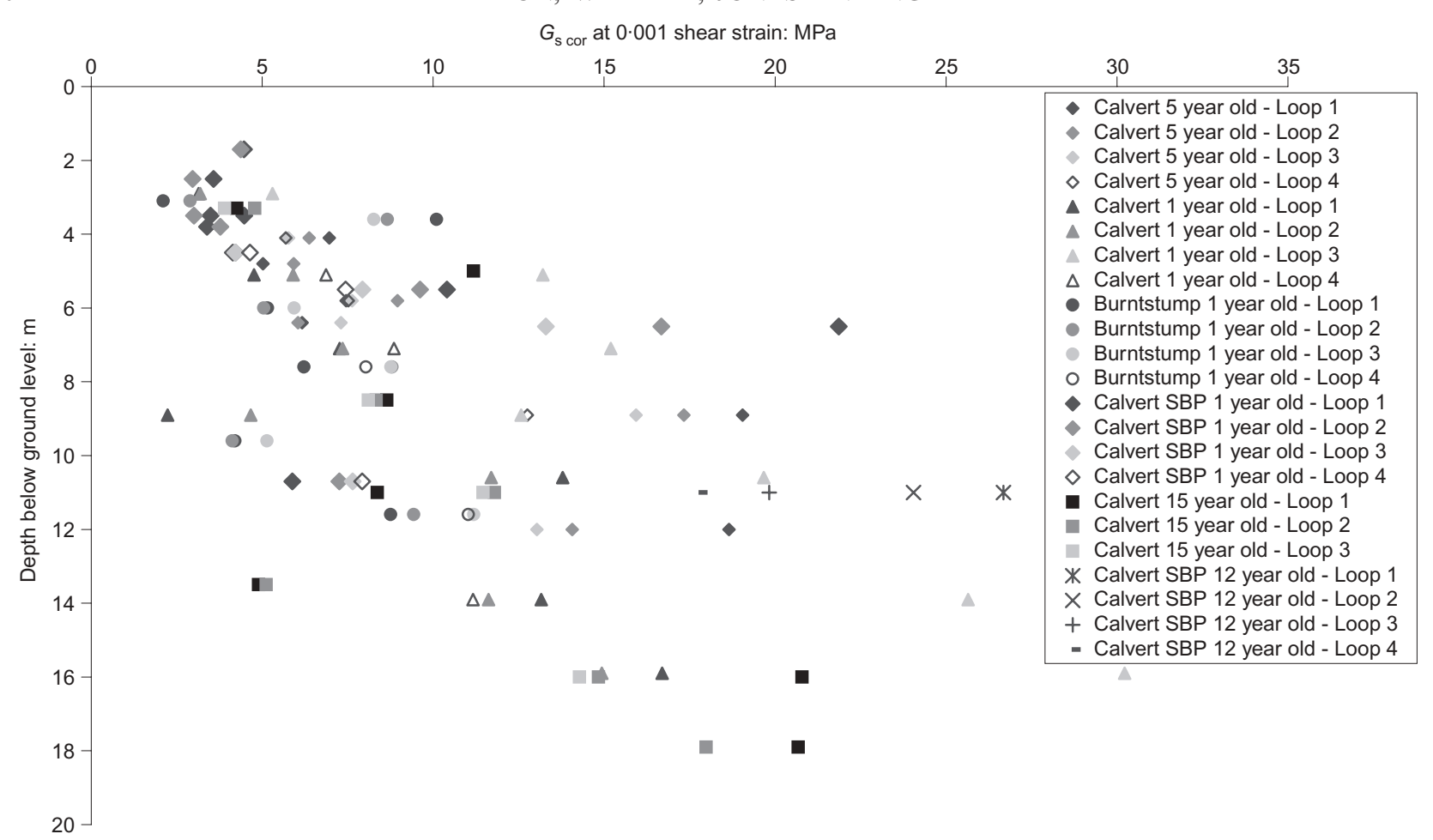

Fig. 12. Secant shear modulus at $0 \cdot 001$ shear strain corrected for stress level plotted against depth (all tests)

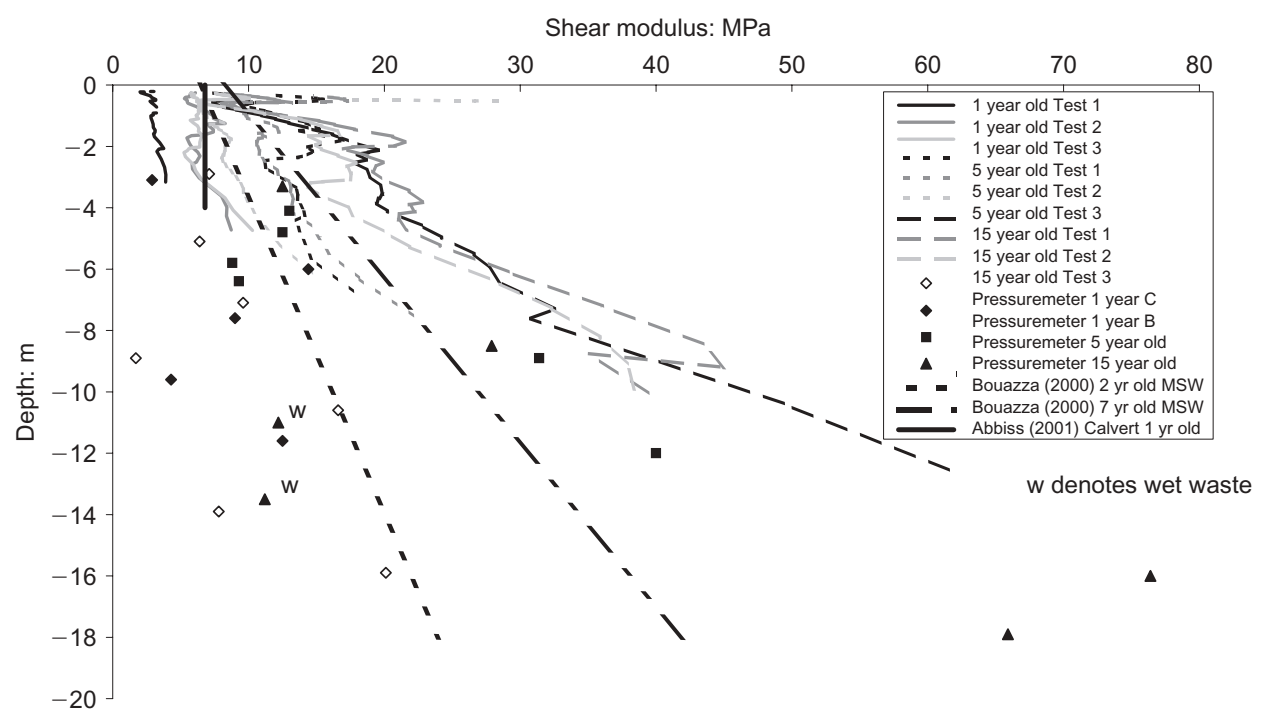

Fig. 13. Comparison of small-strain shear modulus calculated from continuous surface wave method and first unload-reload loops from pressuremeter tests (fresh and older waste)

MSW. Three tests were conducted at each site, and these show good repeatability. The depths of measurement are related to the stiffness of the material, and this explains why the 1 year old waste, with the lowest stiffness, has the smallest depth of data and the 15 year old stiffest waste the greatest depth. All the profiles show increasing stiffness with depth. The tests at locations of the 5 and 15 year old MSW show a high stiffness near the surface resulting from compaction of the clay cover. Also shown are results for fresh MSW obtained using the same technique by Bouazza \& Kavazanjian (2000) for landfill sites in Australia and USA, and by Abbiss (2001) for tests at Calvert. Considering the inevitable scatter in the pressuremeter data due to disturbance and variability of MSW, there is good agreement. The continuous surface wave method tends to average out local variability and hence is less likely to indicate extremes of stiffness. The values for fresh MSW for Calvert and Burntstump obtained in this study and those reported in the literature-Abbiss (2001) for 1 year old waste and Bouazza \& Kavazanjian (2000) for 2 year old MSW-increase with depth at similar rates and are in a clearly defined range. The 5 year old Calvert and 7 year old Bouazza \& Kavazanjian (2000) continuous surface wave method values and the pressuremeter stiffnesses also show general agreement, as do the 15 year old waste surface wave and pressuremeter values, although there is large variability of the pressuremeter values. This is demonstrated by the two low pressuremeter stiffnesses obtained for waste that was recorded as being locally wetter.

It should be questioned whether this good agreement is 
fortuitous. It would be expected that the pressuremeter modulus values would be lower than those calculated from shear wave velocities because the former are not true $G_{0}$ values. In addition, the expected (but not proven) anisotropic nature of MSW, which results from the method of placement, means that the two techniques could be measuring different modes of stiffness. Pressuremeter tests would be controlled primarily by horizontal properties $\left(G_{\mathrm{hh}}\right)$ and measured shear wave velocity by vertical properties $\left(G_{\mathrm{v}}\right)$ of the waste. It has been proposed by Abbiss (2001) that the horizontal stiffness of MSW will be larger than the vertical stiffness. It is possible that the pressuremeter values for 0.0001 strain are underestimating $G_{0}$, and that this is being balanced by the fact that they are horizontal stiffness values, which should be larger than the vertical stiffness values obtained from the shear wave velocity measurements (i.e. the underestimate balances the difference between $G_{\mathrm{hh}}$ and $\left.G_{\mathrm{v}}\right)$. Only further testing will answer this question.

\section{Differences between fresh and older MSW}

Information is required on changes in MSW mechanical behaviour resulting from degradation, for use in the assessment of long-term landfill performance. The older waste tested in this study varied in age from 12 to 15 years. The results indicate that the older waste has higher in situ stresses $\left(P_{0}^{\prime}\right)$ than fresh waste (Fig. 3) but Figs 9, 10 and 12 are consistent in showing that, for a given stress, the older material is less stiff than the fresh waste. The key issue is whether the measured differences between fresh and older waste are due to the degradation process or to differences in the original composition of the waste and the method of placement. Watts et al. (2002) present data for changes in the constituents of UK municipal solid waste from 1935 to 2000. This shows that in 1985 , when the older waste at Calvert was deposited, typically there was approximately $7 \%$ less plastic in the waste than in the late 1990s, when the fresh waste was placed, and $7 \%$ more vegetable matter. The control that specific constituents have on behaviour is an important consideration when assessing the implication of future changes in the waste stream (e.g. due to reuse, recycling, and mechanical and biological pre-treatment). Further work is required to establish the relative contributions to mechanical behaviour of waste composition and degradation.

\section{CONCLUSIONS}

An optimum procedure has been developed for carrying out pressuremeter tests in MSW based on using an HPD in a preformed test pocket. Tests have been conducted in fresh and partially degraded MSW deposits, with tests on fresh MSW carried out at two landfills. The MSW tested can be considered to behave as a drained reinforced particulate material. Disturbance means there is limited confidence in estimated cavity reference pressures and initial shear modulus values, and the lack of an appropriate analytical approach means that values of shear strength could not be obtained. Measurement of shear stiffness has proved successful. Values of secant shear modulus $G_{\mathrm{s}}$ have been obtained from series of unload-reload loops carried out during each test. A clear relationship has been found between secant shear modulus calculated for a reference strain and depth. Stiffness increases with cavity strain (i.e. in the second, third and fourth loops) resulting from drained cavity expansion of the MSW, which causes increased effective stress, density and hence stiffness. Results for fresh MSW from two landfill sites show close agreement. A plot of secant shear modulus at 0.001 shear strain against mean stress at the start of an unload-reload loop gives a linear relationship of increasing stiffness with mean stress.

Good agreement has been found between $G_{\mathrm{s}}$ at 0.0001 strain and $G_{0}$ values measured at the location of the Calvert pressuremeter tests using the continuous surface wave method, and they are also comparable to the limited amount of information in the literature. Secant shear modulus values normalised by mean stress produce a narrow band of results for all fresh MSW over a range of shear strains (0.0001 to $0 \cdot 01)$. Shear modulus values of the partially degraded 15 year old MSW are on average lower than those of the fresh MSW for the same mean stress. It is not clear whether this is due to degradation or to differences in the original waste composition. Further work is required to establish the relative contribution of the two factors.

Assessment of barrier integrity is a key element of landfill design. Measurements of MSW shear stiffness are needed for use in numerical models of waste/barrier interaction. Further information on the mechanical properties of MSW is required in order to assess the performance of current designs and to enable the development of new rigorous landfill lining systems.

\section{ACKNOWLEDGEMENTS}

The work described in this paper was funded by a research grant from the UK Engineering and Physical Sciences Research Council (GR/M33570). All pressuremeter tests were conducted by Cambridge Insitu. Thanks are due to Golder Associates (UK) Ltd, the Environment Agency (England and Wales), Shanks and Waste Recycling Group for their support, and GDS Instruments Limited for carrying out the continuous surface wave velocity measurements. Special thanks are due to Andrew Connell for his help with the drilling operations.

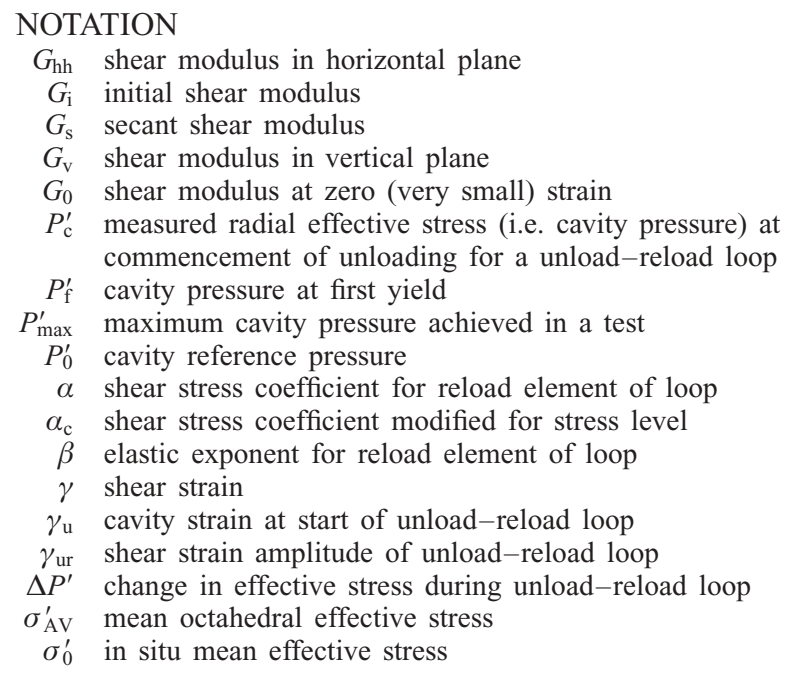

\section{REFERENCES}

Abbiss, C. P. (2001). Deformation of landfill from measurements of shear wave velocity and damping. Géotechnique 51, No. 6, 483-492.

Bellotti, R., Ghionna, V., Jamiolkowski, M., Robertson, P. K. \& Peterson, R. W. (1989). Interpretation of moduli from self-boring pressuremeter tests in sand. Géotechnique 39, No. 2, 269-292.

Bolton, M. D. \& Whittle, R. W. (1999). A non-linear elastic/ perfectly plastic analysis for plane strain undrained expansion tests. Géotechnique 49, No. 1, 133-141.

Bouazza, A. \& Kavazanjian, E. (2000). Characterization of municipal solid waste sites using the continuous surface wave method. 
Proceedings of the International Conference on Geotechnical and Geological Engineering, GeoEng 2000, Melbourne (CD-ROM).

CEC (1999). Directive. 1999/31/EC on the Landfill of Waste. Official Journal of the European Union, L 182, 1-19.

Dixon, N. \& Jones, D. R. V. (2005). Engineering properties of municipal solid waste. Geotextiles and Geomembranes 23, No. $3,205-233$.

Dixon, N., Jones, D. R. V. \& Whittle, R. (1999). Mechanical properties of household waste: in situ assessment using pressuremeters. Proc. 7th Int. Waste Management and Landfill Symp. Sardinia 3, 453-460.

Dixon, N., Ng'ambi, S. \& Jones, D. R. V. (2004). Structural performance of a steep side slope landfill lining system. Proc. Instn Civ. Engrs Geotech. Engng 157, No. 3, 115-125.

Gotteland, P., Lemarechal, D. \& Richard, P. (1995). Analysis and monitoring of the stability of a domestic waste landfill. 5th Int. Landfill Symp., S. Margherita di Pula, Cagliari, Italy, 777-787.

Janbu, N. (1963). Soil compressibility as determined by oedometer and triaxial tests. Proc. 3rd Eur. Conf. on Soil Mech., Wiesbaden 2, 19-24.

Jessberger, H. L. (1994). Geotechnical aspects of landfill design and construction. Part 2: Materials parameters and test methods. Proc. Instn Civ. Engrs Geotech. Engng, 107, 105-113.

Jones, D. R. V., Dixon, N. \& Storey, S. (2002). Assessment of the stability of landfill lining systems. Proc. Waste 2002, Integrated Waste Management and Pollution Control: Research, Policy and Practice, Stratford-upon-Avon, 683-692.

Koerner, R. M. \& Soong, T.-Y. (2000). Stability assessment of ten large landfill failures. Advances in transportation and geoenvironmental systems using geosynthetics: Proceedings of sessions of GeoDenver 2000, ASCE Geotechnical Special Publication No. 103 , pp. 1-38.

Marsland, A. \& Randolph, M. F. (1977). Comparison of the results from pressuremeter tests and large in situ plate tests in London Clay. Géotechnique 27, No. 2, 217-243.

Moxhay, A. L., Tinsley, R. D. \& Sutton, J. A. (2001). Monitoring of soil stiffness during ground improvement using seismic surface waves. Ground Engng 34, No. 1, 34-37.

Robertson, P. K. (1982). In situ testing of soil with emphasis on its application to liquefaction assessment. $\mathrm{PhD}$ thesis, University of British Columbia.

Watts, K. S., Charles, J. A. \& Blake, N. J. R. (2002). Settlement of landfills: measurements and their significance. Proceedings Waste 2002, Integrated Waste Management and Pollution Control: Research, Policy and Practice, Stratford-upon-Avon, 673-682.

Whittle, R. W. (1999). Using non-linear elasticity to obtain the engineering properties of clay: a new solution for the self-boring pressuremeter test. Ground Engng 32, No. 5, 30-34. 